\title{
Adoption of Introduced Homestead Agro-Forestry Technologies in Lemo Woreda, Hadiya Zone, Southern Ethiopia
}

\author{
Yohannes Horamo $^{1}$, Munyaradzi Chitakira ${ }^{2}$, Kowiyou Yessoufou ${ }^{3}$, Girma Woldemichael ${ }^{4, *}$ \\ ${ }^{1}$ Department of Natural Resources Management, Wachemo University, Hosana, Ethiopia. \\ ${ }^{2}$ Department of Environmental Sciences, University of South Africa, Florida, South Africa. \\ ${ }^{3}$ Department of Geography, Environmental Management and Energy Studies, Auckland Park 2006, University of Johannesburg, \\ South Africa. \\ ${ }^{4}$ Department of Environmental Science, Wachemo University, Hosana, Ethiopia.
}

How to cite this paper: Yohannes Horamo, Munyaradzi Chitakira, Kowiyou Yessoufou, Girma Woldemichael. (2020) Adoption of Introduced Homestead Agro-Forestry Technologies in Lemo Woreda, Hadiya Zone, Southern Ethiopia. International Journal of the Science of Food and Agriculture, 4(3), 278-292. DOI: 10.26855/ijfsa.2020.09.008

Received: July 18, 2020

Accepted: August 10, 2020

Published: August 24, 2020

*Corresponding author: Girma Woldemichael, Department of Environmental Science, Wachemo University, Hosana, Ethiopia.

Email: girmawolde886@gmail.com

\begin{abstract}
Homestead is land use system in which multi-purpose trees and shrubs are found in close association with perennial or annual agricultural plants and with animals. Lack of study on adoption and the processes involved impeded the successful introduction and adoption of various agro-forestry practices and other rural technologies in rural communities. Homestead agro-forestry technologies (HAFT) have been introduced and their adoption by farmers is not clearly known and their effects have not yet been investigated and documented in the study area. Despite that, this study was thus designed to study on introduced HAFT with the aim to assess the adoption of introduced HAFT in order to assist the development of homestead agro-forestry in the most effective and efficient way. A structured based questionnaire was used to collect data on farmers' adoption of the introduced HAFT. Using random sampling a total of 131 households were selected for interview. For data analysis, the Statistical Package for Social Science (SPSS) was used. According to the respondents, the reasons for adoption of HAFT were: (1) provision of income, (2) source of food, (3) biomass need, (4) need for organic fertilizer, (5) fodder and (6) soil and water conservation, whereas the reasons for not adopting HAFT were: (1) shortage of resource capacity, (2) lack of awareness and (3) shortage of water. The study revealed that HAFT adoption was progressive in the first five years. Wealth status, level of education and land size at $(\mathrm{p}<0.05)$ and similarly distance from nursery and credit facilities at $(\mathrm{p}<0.1)$ are statistically significant factors influencing adoption of HAFT, whereas other 9 factors (age, sex, family size, land tenure, extension service, incentives, knowledge about HAFT, labor and distance from market) are not statistically significant. In general, fostering research and education to enhance capacities and skills in order to reduce uncertainties with regard to HAFT seems necessary.
\end{abstract}

\section{Keywords}

Adoption, Agro-Forestry, HAFT, Statistically, Significant

\section{Introduction}

The forest cover in Ethiopia, which at one time might have occupied as much as 35\% of the country, according to the woody biomass inventory strategic planning project (WBISPP), has now been reduced to about 3.6\% [1]. The major 
problems are the annual rate of deforestation that is estimated to range from 163,000 ha to 200,000 ha, which is much higher than that of annual average of planting, i.e., 2000 ha, an acute lack of information about farm-forestry practices, limited research and an absence of technical extension to support farm tree growing. It is now recognized that growing trees in the agricultural landscape is probably the only sustainable way in which the production of poles and firewood can be increased [2].

The cultivation of trees and agricultural crops in intimate combination with one another (commonly called Agro-forestry) is an ancient practice used by farmers throughout the world. It is clear from history that agro-forestry is a new name for a set of old practices [3]. Farmers have nurtured trees on their farmland pasturelands and around their homes. Neither the concept nor the practice of agro-forestry is new. There are traditionally very intensive forms of agro-forestry. For example, agro-forestry of Gedeo in SNNPR has production capacity comparable to that of most high-input agricultural systems [4]. It is commonly agreed that, agro-forestry, for a long period of time, has provided the services of sustained soil fertility, soil conservation, increased yield, reduced risk of crop failure, fuel and construction wood, fruits, medicines, food, fodder and a source of income similar to [5]. In general, agro-forestry serves for the greater fulfillment of the socioeconomic needs of local people. It is also well known and universal truth that trees outside forest areas provide environmental services. For instance, shelterbelts and trees on farmlands protect the soil against the drying effect of winds. Moreover, as stated by [6] and [7] "agro-forestry", not only contributes to food security and soil conservation, but also has a remarkably great role in conserving biodiversity.

Recently, attention has been given to socio-economic studies related to the adoption of agro-forestry technologies. Agro-forestry research to date has predominantly focused on the biophysical aspects, with attention given mainly to yield benefits from researcher-managed agro-forestry plots. In most cases, comparisons are made only on the crop yield benefits from agro-forestry technologies, which disregard the farmer's overall loss in crop production through planting part of the farm with trees [8]. This results in reduced agricultural productivity and contributes for low adoption of agroforestry technologies.

According to information from the [9] in the SNNPR (Southern Nations, Nationalities and Peoples Regional) State of Ethiopia, agriculture is the mainstay of $90 \%$ of the population, where there are about 2.4 million rural households. The average landholding of farmers in the region is $<1 \mathrm{ha}$, with a high degree of fragmentation in most areas, which aggravates the decline in soil fertility. The degradation and deterioration of the productivity of the land has greatly impacted the livelihood of the community in the region. The above evidences and reviews of studies indicate that the importance of local and specific studies to identify the socio-economic, physical and technical factors. The factors may be barriers to the adoption of agro-forestry technologies in general and homestead agro-forestry technologies (HAFT) in particular.

In Hadiya zone, particularly in Lemo Woreda various agro-forestry technologies for soil conservation have been carried out for a number of years by government and World Food Program (WFP). According to a report from the zonal office of Agriculture and Rural Development, many hectares of land were covered by tree seedlings and by soil conservation structures. In addition, since 2004 more HAFT have been introduced and are still being in introduction, but its adoption by farmers at the early stage is not clearly known and its effects have not yet been investigated and documented in the Woreda. Limited information is available on the adoption of such technologies in the study area. In spite of that, this study has been designed to focus on introduced HAFT in the first five years and the features of the increasing importance of agro-forestry technologies in general and HAFT in particular. The present investigation was intended to assess the adoption of introduced HAFT in the study area with the following objectives: (1) To investigate the approaches used by the Woreda to facilitate HAFT adoption; (2) To assess the overall perception of local people towards introduced HAFT; (3) To identify factors influencing the adoption of introduced HAFT; and (4) To assess the amount of HAFT adopters and non-adopters in the study area.

\section{Research Methodology}

\subsection{Design of the Research}

The type of the study governs the choice of the study design. In this study, the pragmatic (matter of-factual) world outlook or rational approach was suitable since it is factual-world practice-oriented and problem-centered [10]. In this study, a mixed methods design that is, a mix of quantitative and qualitative approach were employed for collection of data. This study adopted the pragmatism philosophic approach [10].

\subsection{Description of the Study Area}

This study was conducted in Lemo Woreda, Hadiya zone, Southern Ethiopia. Geographically, the study area is located in $07^{\circ} 41^{\prime} \mathrm{N}$ Latitude and $037^{\circ} 31^{\prime} \mathrm{E}$ Longitude. Topography of the study area is rugged high land and hilly areas with range of slope from 2-35 percent. Generally, the terrain is mountainous, undulating and broken type that is very much prone to soil erosion. According to Gilmour [11], land-use planning the soil types or the distribution of soil units in study area is sand sandy loam, loam and clay. As it has been indicated above, the most widely distributed or that 
covers large area is loam. They are distinguished by high amount of clay and these soils are high fertile and probably well-drained.

The Woreda is found in "Woina Dega" agro-climatic zone with altitudinal range of 1,950-2,400 meter above sea level. It has a temperature range of $15-18^{0} \mathrm{C}$ and an average rainfall is $1,150 \mathrm{~mm}$. In the study area, there are a number of rivers and seasonal streams that drain to the area. They supply water for both drinking and sanitation purposes.

The activities and intervention of human being have influenced the natural vegetation in the study area greatly. Farmers are already adapted to planting of some tree species in the Woreda, to meet the demands for wood need. This is actually dominated by different types of Eucalyptus species.

The Woreda has a population of 207,469, of which 103,576 are male and 103,893 female. The dominant land-use types in the Woreda are sedentary mixed farming, whereby the cultivated land accounts for $89 \%$ of the total land area. This in turn indicates that there is great pressure on land. The area practices complete integration of trees, crop and animal production that is similar to Ilany, et al. [12].

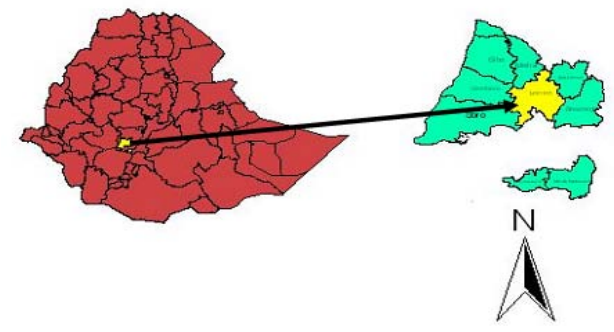

Figure 1. Location of Lemo Woreda in Hadiya zone, Ethiopia (Source: Survey result).

\subsection{Sample Size Determination}

According to [13], the statistical formula used to determine the sample size was

$$
n=\frac{z^{2}(p * q)}{e^{2}}
$$

Where, $\mathrm{n}=$ the sample size, $\mathrm{z}=$ Standard error associated with the chosen level of confidence $\mathrm{p}=$ estimated proportion in the population, $\mathrm{q}=(100-\mathrm{p})$ and $\mathrm{e}=$ acceptable error (Table 1$)$, but the entire population of professionals working in line with HAFT was taken (Table 2)

Table 1. Sample size of Hhs of adopters and non-adopters

\begin{tabular}{cccccccccc}
\hline \multirow{2}{*}{ Name of PAs } & \multicolumn{3}{c}{ Adopters } & \multicolumn{3}{c}{ Non-adopters } & \multicolumn{3}{c}{ Total } \\
& Rich & Medium & Poor & Rich & Medium & Poor & Rich & Medium & Poor \\
\hline Ana-ballesa & 2 & 2 & - & 1 & 11 & 24 & 3 & 13 & 24 \\
Haysie & 5 & 8 & 5 & 1 & 6 & 6 & 6 & 14 & 11 \\
Lissana-senna & 4 & 8 & 7 & - & 17 & 24 & 4 & 25 & 31 \\
Total & $11(8 \%)$ & $18(14 \%)$ & $12(9 \%)$ & $2(2 \%)$ & $34(26 \%)$ & $54(41 \%)$ & $13(10 \%)$ & $52(40 \%)$ & $66(50 \%)$ \\
Grand Total & & $41(31 \%)$ & & & $90(69 \%)$ & & & $131(100 \%)$ & \\
\hline
\end{tabular}

(Source: Survey result)

Table 2. Sample size of professionals’ survey

\begin{tabular}{|c|c|c|c|}
\hline \multirow{2}{*}{ Name of employer organization } & \multicolumn{3}{|c|}{ No. of respondents } \\
\hline & Male & Female & Total \\
\hline \multicolumn{4}{|l|}{ MOA } \\
\hline - $\quad$ Regional Bureau & 3 & - & 3 \\
\hline - $\quad$ Zone Department & 4 & - & 4 \\
\hline - Woreda Experts & 6 & - & 6 \\
\hline - $\quad$ DAs (Development Agents) & 7 & 1 & 8 \\
\hline UN-WFP (Region) (United Nations-World Food Program) & 1 & - & 1 \\
\hline PPRO (Zone) Participatory Poverty Reduction Organization) & 1 & - & 1 \\
\hline Total & 22 & 1 & 23 \\
\hline
\end{tabular}

(Source: Survey result) 


\subsection{Data Collection}

Lemo Woreda has thirty three peasant association (PAs), of which three PAs was selected purposively for primary data collection based on introduced agroforestry technologies in order to avoid peasant associations without introduction of agroforestry technologies. Key informants who include the knowledgeable elderly men and women, religious and opinion leaders in the community were selected from the PAs by using the purposive method of sampling for an informal survey. Discussion was also made with Woreda natural resource management professionals in the selection of the appropriate locations and households in issues of homestead agro-forestry technologies (HAFT) for this study. For formal survey 131 households (Hhs) were selected using stratified random sampling method based on wealth-rank of adopters and non-adopters category (Table 1).

The data were collected from both primary and secondary sources. Also field observation was done to reveal the existing situation and cross checked the peoples' opinion with the real conditions in the field. The primary data collection was carried out by employing structured questionnaires which were pretested in the field for interviewing sample households and discussion of key informants. The methods also included collection of secondary data at three levels (Zone, Woreda and PAs) and by reviewing literatures. Formal survey from the professionals who are engaged or involved in introducing HAFT or working in line with HAFT were provided with structured questionnaires of hand mailed questionnaires on a certain day or within a limited period (Table 2).

\subsection{Data Analysis}

Data were analysed by means of the Statistical Package for Social Science (SPSS) software version 24. The results were presented as descriptive statistics showing the number of households corresponding to their answers usually expressed as percentages and means. Regression (with multi-colinearity test for factors influencing) analysis was carried out. The data that generated from key informants were analyzed by using prioritizing techniques to identify key constraints and intervention points.

\section{Results and Discussion}

\subsection{The Approach Used to Facilitate the Adoption of HAFT}

The concept of homestead agro-forestry development is simple. According to the information obtained from LWOAaNR the approach, possible interventions and procedures followed all through introduction of HAFT were investigated. According to this investigation, it is essentially an approach to help farmers to help themselves. The expectation is to improve homestead productivity in terms of farm income, food, biomass, and at the same time achieve much needed soil and water conservation. It is essentially a participatory approach, whereby the farmer and his family are the main actors and decision makers which is similar to Suyanto et al. [14]. This is also an integrated multidisciplinary approach, in which experts from various disciplines at the Woreda level work together in organizing required inputs and in providing technical assistance to the farmer in implementing the programme on the homestead, by following a step-by-step process. This is based on the objectives, on problems on the homestead and on the requirements of the farmer and his family. The components of the approach were implemented on the homestead according to farmers' requirements.

An adopter is a farmer who has used these components while non-adopter is one who did not use. The following major components have been identified. These are: Multipurpose tree-planting, live fencing, soil and water conservation, construction of water-harvesting structures, horticultural improvement, animal husbandry and poultry and compost preparation as the main ones together with related activities using the following possible interventions:

1) Demonstration of the effect of row planting to a farmer on his homestead, by following the same procedure as for contour cultivation and with described planting techniques. In agreement with the farmers, working out a suitable rotation with crops he wishes to grow on homestead land should be encouraged, as this does not need extra inputs. Many farmers grow more than one crop on the same plot of land at the same time, but separately in small blocks. In relation to this, inter- and strip cropping was demonstrated by planting these crops.

2) Encourage the farmers to plant suitable multipurpose trees or shrubs on the homestead. Provide them with seeds or seedlings of suitable plant species. These are tree or shrub species that provide food, fodder, and fuel-wood; assist the farmer to establish and manage these tree crops efficiently.

3) Assist the farmer to use alternative sources of fuel-wood, by growing fuel-wood on the homestead, thus saving valuable cow dung and crop residues for soil improvement. The cow dung and urine from the cattle shed must be collected and used as manure for making compost, together with crop residues and other green materials available on the farm. In addition, tip of branches from trees used for animals feed, which are unsuitable as animal feed, can be used as a source of organic matter.

4) Demonstrate simple techniques of preparing compost from all sources of organic matter on the homestead. Also, advise farmers to apply organic manure to the land with or without chemical fertilizer, to obtain high crop yields and 
reduce soil erosion at the same time.

5) Practice minimum tillage on homesteads where soil is light and easy to work, and where manual weeding can be used to reduce weed competition. Demonstrate improved crop and soil improvement and management practice to farmers. Assist farmers in managing and utilizing biomass.

6) Encourage farmers to reduce livestock numbers and to improve per capita production by following improved management practices. Assist farmers in growing suitable forage grasses, legumes and legume fodder trees on the homestead. Advise and assist farmers to organize stall feeding and fattening of selected animals. Help farmers in growing and collecting feed from various sources on the homestead. Advise and assist farmers in improving poultry. Help them to obtain better breeds of bird (hens). Home economists and other experts can help the farmer and his family in many ways. To start with, they should be taught to improve diet, health and hygiene by using the products and income generated on the homestead.

Various steps that were followed in implementing the possible intervention was: discussing the proposal with staff at regional, zonal and Woreda levels, Preparing a development plan, organizing material inputs in advance, Implementing the programme on the homestead, Training of field staff and farmers, Monitoring, evaluation and review of the programme.

During the process of HAFT introduction or adoption, all of these are put into practice with the convinced farmers on the exiting problems and the successful homesteads playing important part in demonstrating and convincing other farmers of the values of HAFT. In yearly basis, in number and percentage, i.e., 2004-3(0.2\%), 2005-24(1.3\%), 2006-89(5\%), 2007-167(10\%) and 2008-284(21\%), adopters recorded and the change of growth is $0.2 \%, 1 \%, 3.7 \%$, $5 \%, 11 \%$, respectively. In addition, The results of the survey of professionals regarding the process of introducing HAFT, showed that the provision of inputs had the greatest impact on the introduction process (100\%), awareness creation and technical advice were $91 \%$ and $83 \%$ effective, respectively. Preparation of field days (74\%) and provision of agricultural tools (65\%) also had a considerable effect (Table 4).

The findings indicated (Table 3 and Figure 2); the course of adoption in the study area was tolerant. The introduction of HAFT began in 2004. In this year, only three farmers, one in each peasant association (PA), used these technologies. In year 2005, only 24 farmers used HAFT. This did not differ considerably from the number of 2004 adopters. This may be because of early stage of awareness about HAFT [15]. In 2006 and 2007, good progress was observed, with a record of 89 and 167 adopters, respectively. In 2008, a very good result was recorded, i.e., a total of 284 farmers accepted the technologies of homestead agro-forestry. This shows that the process of introduction of HAFT was progressive. The results indicated that the total number of adopters was $567(31 \%)$ from the total number of farmers $(1,847)$ in the study PAs.

Table 3. Peasant associations versus adopters on a yearly basis

\begin{tabular}{ccccccc}
\hline Peasant Associations & & \multicolumn{3}{c}{ Years } & Total \\
\hline Ana-ballesa & 2004 & 2005 & 2006 & 2007 & 2008 & 59 \\
Haysie & 1 & 3 & 14 & 31 & 10 & 246 \\
Lissana-senna & 1 & 4 & 6 & 56 & 179 & 262 \\
Total & 1 & 17 & 69 & 80 & 95 & 567 \\
\hline
\end{tabular}

(Source: Survey result)

Table 4. Professionals survey result in the process of introducing HAFT

\begin{tabular}{cc}
\hline Process of HAFT introduction & Number (n) and percentage (\%) $\mathrm{n}=23$ \\
\hline Creating awareness & $21(91 \%)$ \\
Providing seeds and seedlings of (sowing and planting materials) & $23(100 \%)$ \\
Technical advice to use compatible trees with crops & $19(83 \%)$ \\
Showing or demonstrating and preparing field days & $17(74 \%)$ \\
Providing agricultural tools & $15(65 \%)$ \\
Choosing model farmers & $13(57 \%)$ \\
Giving prize for best ones & $11(48 \%)$ \\
\hline
\end{tabular}

* Owing to multiple responses in some cases percentage do not sum to 100 (Source: Survey result). 


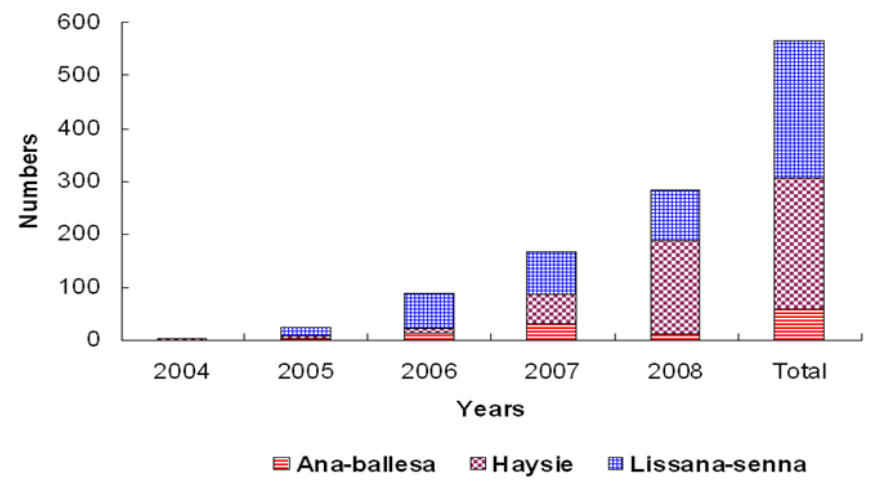

Figure 2. Peasant associations versus adopters' on yearly basis (Source: Survey result).

Wealth status had an influence on HAFT adoption. The wealth status of a household or the wealth of a rural community is clearly observable or measurable. It is not in money form to be hidden, but it can be seen by every assessor. That is to say, the land can be measurable, livestock can be counted, and homestead resources can also be counted and measured. It is also possible to observe housing conditions. For the adoption of HAFT, one needs an adequate resource capacity. A relatively large number of farmers in Haysie PA adopted HAFT, as compared with farmers in the other two PAs (Table 3 and Figure 2). Adoption of HAFT is almost compatible with wealth status in the study PAs. This is in agreement with the findings of [16], and Rogers (2010), that states early adopters are tend to have higher wealth and social status than later adopters.

\subsection{Adoption of HAFT}

The survey of professionals' indicated that HAFT was introduced in relation to soil degradation and a food deficit in the study area. HAFT was introduced as an alternative means of combating this problem. At the time, farmers asked will it require a different way of cultivation? Will it bring me more income? How good it is in general? These were questions that arose at the beginning. But farmers who adopted these technologies said "We have learned that HAFT is high yielding and plays a large part in generating income and securing our food supply”. It was also noted that early-maturing varieties, that they can sell and use for food, were favored. HAFT provides the advantages that they seek. HAFT adopter and non-adopters were investigated and summarized in Table 5.

The reasons why farmers adopted or did not adopt HAFT were investigated. According to this investigation, farmers adopted HAFT because it helps in maximizing the income of farmers in type and amount. It has been found to help farmers to obtain the diversified products that they desired from their own landholding and to protect the fertile topsoil from erosion in a sustainable way. Generally, farmers accept it because it supplies many of the basic needs of the local people. On the other hand, farmers who did not adopt HAFT did so because of a lack of awareness, personal behavior, or because of an initial shortage of capital to invest in these technologies. The results from respondents were summarized (professionals' survey on HAFT Adoption (Table 6 and Table 8), households' survey on HAFT adoption (Table 7 and Table 9).

But the important part of HAFT is that it requires very small inputs of inorganic fertilizer, owing to the package nature of the technologies itself. This is rather encouraging: women, i.e., in agreement with African women farmers in general, obtain lower crop yields than men, but this is due to differences in the intensity of input use, such as inorganic fertilizers [17]. This gap of women may be filled by HAFT. In general, this study indicated that the adoption was very much related with farmers' resource capacity (Table 8 and Table 9). This is in agreement with factors; (culturally attractive perceptions, values and ways of thought) need special analysis in order to obtain an understanding of farmers' behavior, which is often not apparent from situational factors [18].

The result in Table 5 indicated that better adoption is recorded in the medium wealth group. This may be because of the need for an income source to compete with rich farmers. The rich farmers are also proportionately the best adopters. The proportion of poor farmers among adopters is low, which may be due to the shortage of resource capacity that limited them in adopting HAFT (Table 8 and Table 9) which is quite similar to [19]. The need for income, food, biomass use for various purposes, the need for organic fertilizer due to an increase in the cost of inorganic fertilizers and fodder (feed for animals), are the major reasons why farmers adopt HAFT. Moreover, poles and construction materials to be obtained from trees, medicinal value, and vegetables on the homestead, have a higher potential income, possibly encouraging the planting of trees, coupled with vegetables and other crops. This is similar with the findings of [20] [21] [22].

Farmers in the study PAs are involving in introducing HAFT as a complement to the mixed cereal-livestock system existing in Lemo Woreda of Hadiya zone. The results summarized in Table 6 showed the more important motives for 
introducing HAFT as: (1) Generation of income, similar to [23], (2) As a food source, similar to [24] and [23], (3) As biomass for different purposes, similar to [25], (4) Need for organic fertilizer due to an increase in the cost of inorganic fertilizers, similar to [26], (5) for fodder, (6) for soil and water conservation which is similar to [27, and (7) for enhancing land productivity. The most important constraints stated by farmers were: (1) shortage of resource capacity (credit, plastic sheet, farm tools, seedlings, fertilizer, chemicals, etc.), and (2) shortage of land are the most important in the study area.

Table 5. HAFT adopters and non-adopters in the study area

\begin{tabular}{ccccccc}
\hline \multirow{2}{*}{ Wealth group } & \multicolumn{2}{c}{ Ana-ballesa $(\mathrm{n}=40)$} & \multicolumn{2}{c}{ Haysie $(\mathrm{n}=31)$} & \multicolumn{2}{c}{ Lissana-senna (n=60) } \\
& Adopters & Non-adopters & Adopters & Non-adopters & Adopters & Non-adopters \\
\hline A(Rich) & $2(50 \%)$ & $1(3 \%)$ & $5(28 \%)$ & $1(8 \%)$ & $4(21 \%)$ & $0(0 \%)$ \\
B(Medium) & $2(50 \%)$ & $11(30 \%)$ & $8(44 \%)$ & $6(46 \%)$ & $8(42 \%)$ & $17(41 \%)$ \\
C(Poor) & $0(0 \%)$ & $24(67 \%)$ & $5(28 \%)$ & $6(46 \%)$ & $7(37 \%)$ & $24(59 \%)$ \\
Total sum & $4(100 \%)$ & $36(100 \%)$ & $18(100 \%)$ & $13(100 \%)$ & $19(100 \%)$ & $41(100 \%)$ \\
Percent & $10 \%$ & $90 \%$ & $58 \%$ & $42 \%$ & $32 \%$ & $68 \%$ \\
\hline
\end{tabular}

(Source: Survey result)

Table 6. Reasons for adoption of HAFT as perceived by professionals

\begin{tabular}{cc}
\hline Reasons & Number (n) and percentage $(\%)(\mathrm{n}=23)$ \\
\hline Income & $22(96 \%)$ \\
Food Source & $21(91 \%)$ \\
Fodder (feed for animals) & $16(70 \%)$ \\
Biomass used for (Construction, fuel) & $18(78 \%)$ \\
Soil and water conservation & $15(65 \%)$ \\
Enhance land Productivity & $12(52 \%)$ \\
\hline
\end{tabular}

* Owing to multiple responses in some cases percentages do not sum to 100 (Source: Survey result).

Table 7. Reasons for adoption as perceived by farmers

\begin{tabular}{cc}
\hline Reasons & Number (n) and percentage (\%) (n= 41) \\
\hline Income & $41(100 \%)$ \\
Food Source & $35(85 \%)$ \\
Fodder (feed for Animals) & $29(71 \%)$ \\
Need for Biomass for different uses & $33(80 \%)$ \\
Need for organic fertilizer due to an increase of cost for inorganic fertilizer & $30(73 \%)$ \\
\hline
\end{tabular}

* Owing to multiple responses in some cases percentages do not sum to 100 (Source: Survey result).

Table 8. Reasons for not adopting of HAFT as perceived by professionals

\begin{tabular}{cc}
\hline Reasons & Number (n) and percentage (\%) (n=23) \\
\hline Lack of awareness & $16(69 \%)$ \\
Shortage of water & $21(91 \%)$ \\
$\begin{array}{c}\text { Shortage of resource capacity (Credit, plastic sheet, farm tools, seeds } \\
\text { and seedlings, fertilizer and chemicals }\end{array}$ & $23(100 \%)$ \\
Lack of efficient extension service & $10(43 \%)$ \\
\hline
\end{tabular}

* Owing to multiple responses in some cases percentages do not sum to 100 (Source: Survey result). 
Table 9. Reasons for not adopting HAFT as perceived by farmers

\begin{tabular}{cc}
\hline Reasons & Number (n) and percentage (\%) $(\mathrm{n}=90)$ \\
\hline $\begin{array}{c}\text { Shortage of resource capacity (credit, plastic } \\
\text { sheet, farm tools, seed and seedlings, fertilizer and chemicals) } \\
\text { Land shortage and looking for immediate returns }\end{array}$ & $73(81 \%)$ \\
Labor shortage & $54(60 \%)$ \\
Lack of Knowledge & $9(10 \%)$ \\
No Reason & $19(21 \%)$ \\
\hline
\end{tabular}

* Owing to multiple responses in some cases percentage do not sum to 100 (Source: Survey result).

\subsection{Perception towards HAFT}

The adopters were satisfied with HAFT. Survey result of professionals and farmers indicated $100 \%$ were fearful that a market threat (low price) might arise when adoption increased (Table 10), because of market failure that might occur. This was exemplified by farmers with surplus agricultural products in 2001-2002, when a quintal of wheat and "teff", cost 60 and 120 Ethiopian birr, respectively in the study area. Their fears may or may not be real, but do indicate the importance to sustained adoption of HAFT, of price related in the study area. The survey result showed 15\%, 54\%, 26\% and 5\% said HAFT is "good", "very good", "excellent" and "no idea", respectively (Table 11) which is similar to [16] and [27]. On the other hand, key informants stated that the demand for water harvesting is increasing. This could actually be observed in the study PAs. Thus, individuals were trying to construct their own ponds; hand-dug shallow and deep wells. In this respect, they feel or consider that HAFT will involve tedious work (work throughout the year).

Table 10. Farmers perception towards HAFT as perceived by professionals

\begin{tabular}{cc}
\hline Perception & Number (n) and percent (\%) $(\mathrm{n}=23)$ \\
\hline Market threat (low prices ) & $23(100 \%)$ \\
Expectations (Something will be given in relation with HAFT) & $23(100 \%)$ \\
Lack of awareness and knowledge to HAFT & $21(91 \%)$ \\
Shortage of technology supply & $18(78 \%)$ \\
\hline
\end{tabular}

* Owing to multiple responses in some cases percentage do not sum to 100 (Source: Survey result).

Table 11. Farmers perception with respect to HAFT

\begin{tabular}{ccccccccc}
\hline \multirow{2}{*}{ Farmers Response } & \multicolumn{3}{c}{ Peasant Associations } & & & & \\
& \multicolumn{2}{c}{ Ana-ballesa } & Haysie & \multicolumn{2}{c}{ Lissana-senna } & & Total \\
\hline Good & $\mathrm{n}=40$ & $\%$ & $\mathrm{n}=31$ & $\%$ & $\mathrm{n}=60$ & $\%$ & $\mathrm{n}=131$ & $\%$ \\
Very Good & 8 & 20 & 3 & 10 & 9 & 15 & 20 & 15 \\
Excellent & 24 & 60 & 18 & 58 & 29 & 48 & 71 & 54 \\
No Idea & 6 & 15 & 10 & 32 & 18 & 30 & 34 & 26 \\
Total & 2 & 5 & 0 & 0 & 4 & 7 & 6 & 5 \\
\hline
\end{tabular}

* Owing to single responses in all cases percentages do sum to 100 (Source: Survey result).

Also, had it not been for insufficient credit facilities, the adoption would have been successful than was recorded. Market and market opportunities are very important as perceived by farmers and professionals. If there are no market facilities, adoption may not occur. Farmers stated that this was seen in practice in the zone for the "surplus" production of wheat and "'teff", using the extension service in 2001-2002. They stressed that "Production should go together with a marketing facility". If not, "production without a market is like a coffee plant without fruit". In the first place, farmers will only adopt if they perceive that they can feed themselves and sell the production. According to farmers understanding, a market facility had a great positive influence on the adoption of HAFT in the study area. The market now has an insignificant effect, but there is a great fear for the future, as perceived by farmers as well as professionals. 


\subsection{Factors Influencing HAFT Adoption}

The results of independent variables like personal, socio-economic and institutional were investigated, and their influences with respect to the adoption of HAFT (dependent variable) were also analyzed. The results were summarized in the following section.

\subsubsection{Land Size and Land Tenure}

Land is important resource for implementation of HAFT. People who have a large landholding are expected to be more likely to introduce HAFT first than those who have a small landholding. However, the size of landholding is one of the criteria in the study to classify households into poor, medium and rich. The size of landholding reflects wealth in the study area, in which it is true to say that there is no free, open access to land other than by inheritance. Land purchase and sale are completely forbidden, because land is the property of the state and the public. The size of an individual landholding is the area possessed in the past and at the time of land reallocation. Consequently, landholders are forced to maintain their HAFT on their plot of land.

The output of a regression analysis (at $\mathrm{p}<0.05$, Table 16) shows that landholding size significantly affects adoption of HAFT, thus as land size decreases need for intensive farming (HAFT introduction) increases. In addition, for land sizes of $<0.5$ ha adopters are less than non-adopters, 0.6-1ha adopters are equal to non-adopters and 1-2 ha adopters are greater than non-adopters. This in turn indicates land size contributing for wealth as well as for better adopting (Figure 3) which is similar to [28] and [29]. On the other hand, as regards the current land-tenure policy, no fear was mentioned or observed. This may be because of the land-possession certificate given to farmers, which may also be the reason for the absence of hesitation in investing in their plot of land.

\subsubsection{Incentives and Credit Facilities}

Farmers explained that incentives and credit facilities can play an important role in HAFT adoption similar to [17]. They considered that incentives and credit facilities can fill the gap in resource capacity. The survey result indicated 50(38\%) received incentives and 8(6\%) a credit facility. Of the incentives, $16(12 \%)$, 36(27\%), 26(20\%) and 13(10\%) were seed, seedlings, farm tools and plastic sheet, respectively. Owing to the shortage of plastic sheets, only 23(18\%) of respondents had trapezoidal water-harvesting structures and 5(4\%) hand-dug wells. Credit is factor significantly influencing adoption of HAFT in the study PAs (at $\mathrm{p}<0.1$, Table 16). But only $31 \%$ of farmers, who had resources on their hand and access to resources, were able to handle the problem, whereas $69 \%$ of farmers were not in a secure condition or were currently unable to introduce these technologies.

As perceived by the farmers, the important aspect of HAFT is that it requires very small inputs of inorganic fertilizer, owing to the package nature of the technologies itself. Had it not been for its package nature, it may not have been possible to introduce the technologies even where the farmers are rich.

\subsubsection{Extension Services}

The result obtained was almost all farmers accepted that the extension service is complete and effective. The three agro-forestry components (trees, crops and animals) are integrated. The survey results showed that, of 131 households, $121(92 \%)$ and $117(89 \%)$, respectively, of the respondents said that the current extension service or advice was adequate, and that farmers keep in contact with extension agents. 90(69\%) of the respondents knew the importance of HAFT. $66(50 \%)$ of the respondents were trained in applying these technologies, while 122(93\%) were observant of HAFT application, 107(82\%) had heard of it from other farmers and 24(18\%) had heard of it from an NGO such as Participatory Poverty Reducing Organization (PPRO). These are in agreement with the findings of [30] and [31].

In general, it is the result of this study that the adoption was very much related to farmers' resource capacity (Table 8 and Table 9). In addition, the extension service is not a factor significantly influencing adoption of HAFT in the study PAs (Table 16). Also, the survey result indicated that there is still a need to run HAFT in the study area with preconditions. Thus, of the 90 households in the non-adopters' survey, 55(61\%) expected incentives, 35(39\%) not expecting incentives and 71(79\%) expected a credit, and 19(21\%) needed to run HAFT by their own cost. 90(100\%) of respondents are without hesitation for full integration of agroforestry components similar to [17].

\subsubsection{Proximity to Nursery}

Almost all professionals and farmers perceived from past experience that proximity to a nursery influences the adoption of tree planting. Since 2004 (the beginning of the HAFT introduction), they have perceived that the influence of proximity to a nursery is negligible for HAFT adoption, because nurseries were established nearby in each PAs. The household survey indicated that 96(73\%) and 35(27\%), respectively, of the respondents were within 1-2 and 3-4 km of the nursery centre. Moreover, the statistical analysis showed that distance from the nursery had significant influence (at $\mathrm{p}<0.1$, Table 16). On the other hand, according to the key informants $>5 \mathrm{~km}$ away from their home can have an influence. 


\subsubsection{Labor}

The introduction of HAFT requires labor, due to the nature of the work itself. The homestead becomes a labor-intensive workplace. One may need another source of labor in addition to the family. The study has shown that labor was not a problem in the study PAs. As can be seen from the (Table 15), 90\% of households covered their labor needs themselves, whereas only $10 \%$ required additional labor. This is rather encouraging for the adoption of HAFT. The regression analysis also showed that labor was not significant (Table 16). Moreover, according to the discussions of key informants, labor was not a constraint in the study PAs. Men and women can manage the landholding they have, except those who have large landholdings, similar to [32], i.e., a few farmers categorized as "rich". Actually labor is the most important factor in comparison with the others agro-forestry practices in the study area.

\subsubsection{Wealth Status}

Wealth status is very much related to resource capacity. In other words, it is directly related to land and land resources, livestock, money and farm equipment. In the context of the study area, it takes different forms (poor, medium and rich). Regression analysis showed that wealth status had a significant influence (at $\mathrm{p}<0.05$, Table 17 ) on the adoption of HAFT. Wealthier farmers adopted HAFT faster than farmers with limited resource capacity, or than poor farmers. As shown in Figure 4 also show that poor and medium non-adopters are greater than poor and medium adopters; whereas rich non-adopters are less than rich adopters.

\subsubsection{Market and Market Distance}

Almost all of the respondents, professionals (96\%) and households (100\%), indicated that market and market demand have been influencing, and will have a great influence on, the adoption of HAFT in the future. If there are no market facilities, there will even be dis-adoption of HAFT. "Production should be combined with a marketing facility". If not, "production without a market is like a coffee plant without fruit". This indicated that, according to their understanding, the existence of a market facility had a great influence on the adoption of HAFT. In this study, distance from the market did not significant factor affecting adoption (Table 16). This is in agreement with the household survey, which indicated that 20(15\%), 103(79\%) and 8(6\%), respectively, of the respondents were within 2-5, 6-10 and 11-15 km of the market centre. This result may, however, be different for those who are far from the market center.

\subsubsection{Personal Characteristics}

The personal characteristics of farmers may or may not influence the adoption of HAFT as [33]. This was explained as follows: From the total of adopter respondents, 16(39\%) and 25(61\%), respectively, were illiterate and literate. Whereas, as regards non-adopters, 60(67\%) and 30(33\%), respectively, were illiterate and literate. This clearly indicates that learning has a positive effect on the adoption of HAFT. This may be because educational level is closely related to knowledge of HAFT. Educational level can be classified as the factor influencing the adoption of HAFT (at p $<0.05$, Table 16). Also education indicated that illiterate adopters are less than illiterate non-adopters whereas literate adopters are greater than literate non-adopters (Figure 5). On the other hand, age, sex and/or gender and family size were weakly correlated with HAFT adoption. This indicates that age, sex and/or gender and family size do not significantly influence HAFT adoption.

Table 12. Size of land holdings as perceived by farmers

\begin{tabular}{cccccc}
\hline \multirow{2}{*}{ Adoption of HAFT } & \multicolumn{3}{c}{ Size of landholding } \\
& Very small & Small & Enough & Not enough & Total \\
\hline Adopters & $6(14 \%)$ & $14(34 \%)$ & $8(20 \%)$ & $13(3 \%)$ & $41(100 \%)$ \\
Non-adopters & $25(28 \%)$ & $32(35 \%)$ & $9(10 \%)$ & $24(27 \%)$ & $90(100 \%)$ \\
Total & $31(24 \%)$ & $\mathbf{4 6 ( 3 5 \% )}$ & $17(13 \%)$ & $\mathbf{3 7 ( 2 8 \% )}$ & $131(100 \%)$ \\
\hline
\end{tabular}

(Source: Survey result)

Table 13. Land size or holdings in the study PAs

\begin{tabular}{cccc}
\hline Variable- Land Size/holding & Peasant Associations \\
Ana-ballesa $\mathrm{n}=40$ & $24(60 \%)$ & $11(36 \%)$ & Lissana-senna $\mathrm{n}=60$ \\
\hline$<0.5-1$ & $13(33 \%)$ & $14(45 \%)$ & $31(52 \%)$ \\
$>1-2$ & $3(7 \%)$ & $6(19 \%)$ & $24(40 \%)$ \\
$>2$ & 1 & 1 & $5(8 \%)$ \\
Median & & & 1 \\
\hline
\end{tabular}

(Source: Survey result) 
Table 14. Nursery distance as perceived by key informants

\begin{tabular}{|c|c|c|c|}
\hline \multirow{2}{*}{ Variable } & \multicolumn{3}{|c|}{ Peasant Associations } \\
\hline & Ana-ballesa $\mathrm{n}=$ & Haysie $\mathrm{n}=7$ & Lissana-senna $\mathrm{n}=7$ \\
\hline $\begin{array}{l}\text { Proximity to Nursery } \\
\text { Away from the nursery }\end{array}$ & 0 & 0 & 0 \\
\hline Nearby nursery & $100 \%$ & $100 \%$ & $100 \%$ \\
\hline
\end{tabular}

(Source: Survey result)

Table 15. Labor use in the study PAs

\begin{tabular}{cccc}
\hline Labor use & & Peasant Associations & \\
& Ana-ballesa(n = 40) & Haysie(n = 31) & Lissana-senna (n = 60) \\
\hline Family & $36(90 \%)$ & $28(90 \%)$ & $54(90 \%)$ \\
Hired & $0(0 \%)$ & $0(0 \%)$ & $0(0 \%)$ \\
Both (hired and family) & $4(10 \%)$ & $3(10 \%)$ & $6(10 \%)$ \\
\hline
\end{tabular}

(Source: Survey result)

Table 16. Result of regression analysis

\begin{tabular}{|c|c|c|c|c|c|}
\hline Factors & B & S.E. & Wald & Sig & $\operatorname{Exp}(B)$ \\
\hline Age & 0.436 & 0.351 & 1.547 & 0.214 & 1.547 \\
\hline Sex & -0.286 & 1.272 & 0.051 & 0.822 & 0.751 \\
\hline Family Size & 0.129 & 0.187 & 0.475 & 0.491 & 1.137 \\
\hline Education ${ }^{* *}$ & 1.661 & 0.813 & 4.174 & 0.041 & 5.263 \\
\hline Land Tenure & -0.517 & 1.614 & 0.103 & 0.749 & 0.596 \\
\hline Extension Service & -0.747 & 1.349 & 0.307 & 0.580 & 0.474 \\
\hline Credit ${ }^{*}$ & -2.672 & 1.587 & 2.834 & 0.092 & 0.069 \\
\hline Incentives & -0.413 & 0.885 & 0.218 & 0.641 & 0.662 \\
\hline Proximity to Nursery ${ }^{*}$ & -1.544 & 0.915 & 2.848 & 0.091 & 0.214 \\
\hline Land Size Effect ${ }^{* *}$ & -1.540 & 0.727 & 4.487 & 0.034 & 0.214 \\
\hline Knowledge about HAFT & -22.621 & $5,556.262$ & 0.000 & 0.997 & 0.000 \\
\hline Labor & 0.281 & 0.773 & 0.132 & 0.717 & 1.324 \\
\hline Wealth Status ${ }^{* *}$ & 1.476 & 0.635 & 5.404 & 0.020 & 4.377 \\
\hline Distance From Market & 1.530 & 0.948 & 2.606 & 0.106 & 4.617 \\
\hline Constant & 23.817 & $5,556.262$ & 0.000 & 1 & 2.211 \\
\hline
\end{tabular}

( Significant at $\mathrm{p}<0.1,{ }^{* *}$ Significant at $\mathrm{p}<0.05$ ) (Degree of freedom $(\mathrm{df})=1$ ) (Source: Survey result).

Regression analysis indicated that family size and age had no significant effect on HAFT adoption. This is in agreement to that of [34], that states there is no significant difference between tree planters and non-planters (mean family size). Age insignificance is in agreement with [32], that states early adopters are usually not different from later adopters in age. Also as perceived by farmers distance from the nearest nursery center is an important variable that affects the introduction of HAFT in the study PAs. The same is true for landholding size effect. The size of landholdings has an important influence on the choice of tree species [35], and [34], suggested that for the pillar component of agro-forestry (trees), planting or retention would also have been affected by the land holding size (Table 13 and Table 14). The regression output (Table 16) showed that sex and/or gender did not significantly affect the adoption of HAFT is also in agreement with [17]. 


\section{Land Size Vs Adopters}

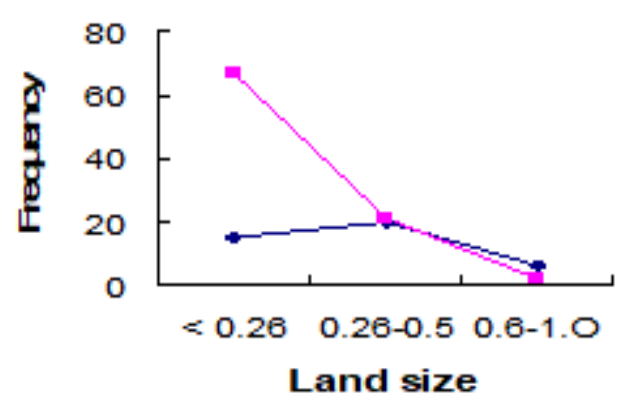

$\rightarrow$ Adonters - - Non-adonters
Land SIze Vs Adoptlon

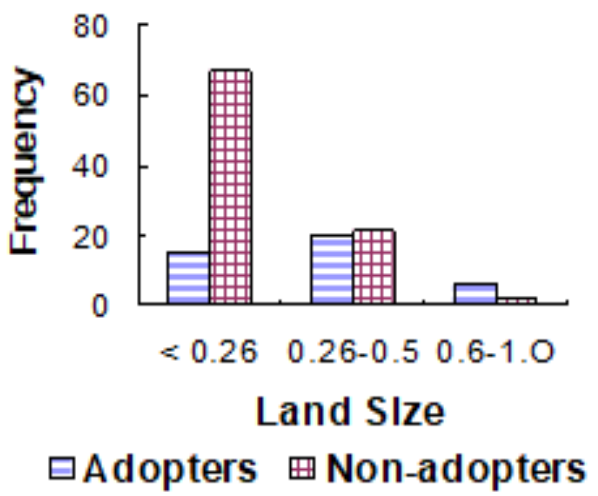

(Source: Survey result)

Figure 3. Land holding versus adopting of HAFT.

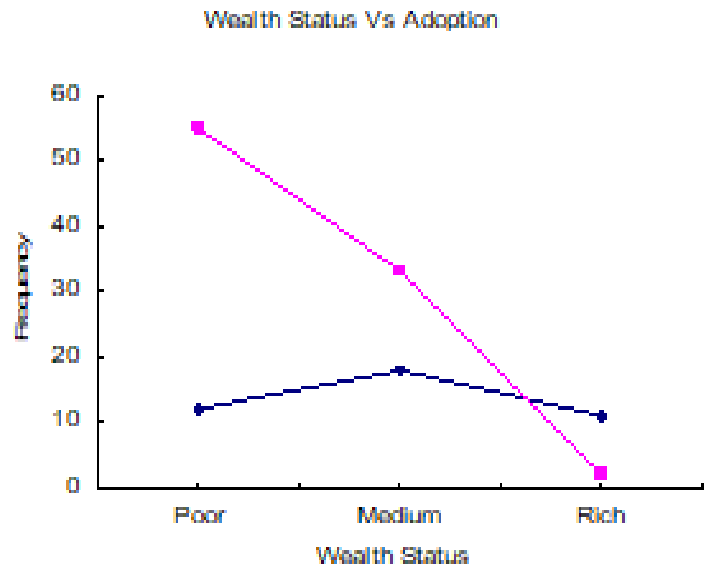

+Woalth Status/ Adapters - - Woalth Status/ Non-adapters
Education Vs Adoption

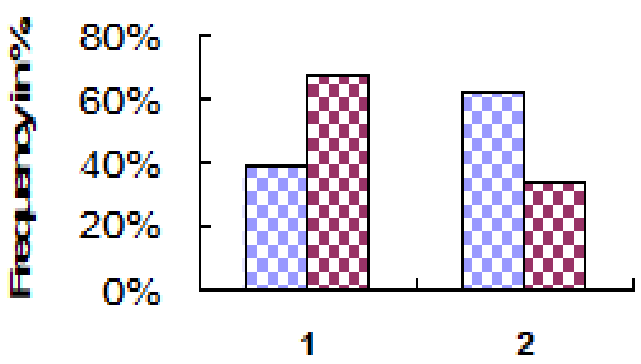

Education

(Source: Survey result)

Figure 4. Wealth status versus adoption.

Figure 5. Education versus adoption.

Landholding size is the basic criterion for classifying wealth status. This is not in agreement with the result obtained, that landholding size is not a reflection of wealth [34]. This study showed that those farmers who have large landholdings also have better wealth status and more adoption of HAFT. In addition, those who had the resource capacity to access inputs of HAFT (seeds, seedlings, and other required inputs) were also adopters.

It is clearly seen that educational level has a positive effect on the adoption of HAFT. This may be because of knowledge and of the behavioural change that education has brought about. Educational level can be classified as factor that significantly influences the adoption of HAFT similar to [36]. This agrees with [32], that states early adopters have more years of formal education than later adopters, and tend to be more literate than are later adopters. Labor, as explained in the results section, does not appear as a major constraint on the adoption of HAFT. Factors such as extension may be very important when introducing HAFT to farmers who are not previously aware of it. HAFT introduction by farmers is also strongly need-dependent, i.e., mostly on the income and food available to household. Extension service contributed more or less to the adoption of HAFT. But for the effective extension services, it would have not have succeeded. Owing to population pressure, farm size in the study area has become so small, that agricultural activities are limited to the homestead. This is in agreement with the fact that homesteads produce an increasingly important supply of food in many countries, as population pressure reduces the amount of land available to each household for food crops [7]. Similarly, according to [37], there will be strong incentives for tree-growing when biomass resources are scarce and population density is very high. In such circumstances, access to off-farm resources is declining and ultimately, there can be an increase in the number of tree species and planting locations in the farming system. In fact, a point may be reached at which farm size becomes so small that tree-planting is again limited to homesteads. 


\section{Conclusion and Recommendations}

\subsection{Conclusion}

Homestead is located in dwelling places, and the survey results lead us to conclude that homestead agro-forestry technologies (HAFT) introduced in homestead function as production system. In the study peasant associations (PAs) remarkably it is found that, farmers in the last two decades have been persuaded to introduce HAFT for multiple purposes. Not just only for one purpose, but the majority of farmers prioritized the livelihoods benefit of HAFT. The major finding of this study from the survey is that food generating is the primary importance in the decision of whether to introduce HAFT or not. It appears, therefore that making HAFT farming more important is a necessary condition for increasing the amount of HAFT introduction in the homesteads, i.e., to effectively compete with other agricultural activities.

Adoption of intensified HAFT in the study PAs would increase households' income and the potential benefits of multipurpose tree planting on the homestead. Given the increased awareness of farmers regarding the potential financial benefit of introducing HAFT, it should be possible to tie together those positive attitudes to a strategy to alleviate the poverty of the rural people.

It has been made clear that farmers' awareness of HAFT introducing programme is slight, and the contribution of extension workers to encourage farmers to introduce HAFT has been encouraging. To maximize the introduction and scaling up of HAFT, professionals and DAs are broadening the activities and work more closely with local farmers. They are disseminating technical information to HAFT users, supply sufficient seed and seedlings of this technologies that fit for the locality. In addition, provide strong and effective institutional support. Moreover, arrange for efficient marketing facilities of the HAFT products so that poor farmers can come forward to enhance these technologies and get proper returns from production. Results also support these concepts, since land available for HAFT introduction is very limited in the study PAs due to an increasing population. Extension workers or development agents are identifying and or assisting in finding land fit for HAFT and takes effective measures. Results of this study suggest showed the same confirmation. Adoption of more systematic HAFT design and careful species selection reduce the difficulties of using homestead land for these technologies and others.

In addition, other factors that influence adoption of HAFT are:

(1) Farmers training centers (FTC) and schools are very good learning centers for changing the communities and training farmers of these days and the future respectively.

(2) Activities that generate income and diversification are more attractive to farmers in the study PAs likely to be adopted faster.

(3) The delay until the income from a new planting begins to pay back these initial costs is a key consideration for most landowners

(4) Integrating trees and shrubs with the other activities on a homestead create additional sources of income and spread farm labor throughout the year.

(5) Involvement of farmers in planning and implementation (genuine participation) at grass root level is vital for success of the HAFT introduction and adoption.

To sum up, it is observed that there are decision making action, changes in knowledge, utilization of knowledge, application of skills, awareness, motivation, feedback, understanding the whole process, and the like is important in the process of HAFT introduction and adoption.

\subsection{Recommendations}

Those who are working in line with HAFT introduction, i.e., regional, zonal and Woreda experts, development agents and farmers should have to share their ideas and experience on enhancing HAFT. Stakeholders' active participation and cooperation, needs to be ensured in the HAFT transfer process. In general, it is suggested that natural resources conservation and development extension workers work more closely with the local people in order to implement HAFT.

Bureau of Agriculture and Natural Resource Development should have to facilitate credit to farmers so as to enhance the adoption of HAFT. Since, credit is an important way of increasing adoption as well as production. Constraints to scaling up adoption of HAFT should be minimized as much as possible. The gradual adoption of HAFT since 2003 does not simply mark technology acceptance, in this aspect farmers are producing more and more for marketing. The most important constraints expressed by farmers: (1) shortage of resource capacity (credit, plastic sheet, farm tools, seedlings, fertilizer, chemicals, etc.), and (2) shortage of land in the study area should have to be improved. Thus enable to encourage or play a great role for the expansion of HAFT. Moreover, HAFT needs may change through time, hence need assessment for it may needs to be carried out regularly.

To address the top questions of farmers (income generating and food security of household) properly and in sustainable way, generally fostering research and education to enhance capacities and knowledge in order to reduce uncertainties with regard to HAFT seems necessary. 


\section{References}

[1] Keenan, et al. (2015). Dynamics of global forest area: Results from the FAO Global Forest Resources Assessment 2015. Forest Ecology and Management, 352, pp.9-20.

[2] Shiferaw, B. A., Okello, J., \& Reddy, R. V. (2009). Adoption and adaptation of natural resource management innovations in smallholder agriculture: reflections on key lessons and best practices. Environment, development and sustainability, 11(3), pp.601-619.

[3] Jose, et al. (2009). Tree-crop interactions in temperate agroforestry. North American Agroforestry: An Integrated Science and Practice. 2nd ed., ed. HE Garrett, pp. 57-73.

[4] Kanshie, T. K. (2002). Five thousand years of sustainability: a case study on Gedeo land use (Southern Ethiopia).

[5] Dagar, J. C. \& Tewari, J. C., eds. (2016). Agroforestry research developments. Nova Science Publishers.

[6] De Clerck, F. A. \& Negreros-Castillo, P. (2000). Plant species of traditional Mayan homegardens of Mexico as analogs for multistrata agroforests. Agroforestry Systems, 48(3), pp. 303-317.

[7] Motuma, T. (2006). Woody Species Diversity of Agricultural Landscapes in Arsi Negelle District, Ethiopia: Implications for Biodiversity Conservation. MSc Thesis.

[8] Zomer, et al. (2009). Trees on farm: analysis of global extent and geographical patterns of agroforestry. ICRAF Working Paper-World Agroforestry Centre, (89).

[9] Ethiopia, C. S. A. (2008). Summary and statistical report of the 2007 population and housing census. Federal democratic republic of Ethiopia population census commission, Addis Ababa, Ethiopia, pp. 1-10.

[10] Creswell, J. W. (2009). Editorial: Mapping the field of mixed methods research. Journal of Mixed Methods Research, 3(2), pp. 95-108.

[11] Gilmour, D. (2016). Forty years of community-based forestry: A review of its extent and effectiveness. FAO.

[12] Ilany, et al. (2010). Using agroforestry to improve soil fertility: effects of intercropping on Ilex paraguariensis (yerba mate) plantations with Araucaria angustifolia. Agroforestry systems, 80(3), pp. 399-409.

[13] Daniel, W. W. (1999). Probability and t distribution biostatistics: A foundation for analysis in health science. Pp. 83-123. John willey and Sons.

[14] Suyanto, et al. (2005). Land tenure, agroforestry adoption, and reduction of fire hazard in a forest zone: A case study from Lampung, Sumatra, Indonesia. Agroforestry Systems, 65(1), pp. 1-11.

[15] Alam, M. \& Sarker, S. K. (2011). Homestead agroforestry in Bangladesh: dynamics of stand structure and biodiversity. Journal of sustainable forestry, 30(6), pp. 584-599.

[16] Meijer, et al. (2015). The role of knowledge, attitudes and perceptions in the uptake of agricultural and agroforestry innovations among smallholder farmers in sub-Saharan Africa. International Journal of Agricultural Sustainability, 13(1), pp. 40-54.

[17] Alao, et al. (2014). Analysis of the impact of production technology and gender on under-utilised indigenous vegetables production in south-western Nigeria. African Journal of Science, Technology, Innovation and Development, 6(1), pp. 51-59.

[18] Parwada, et al. (2012). A review of agroforestry technologies adoption among small-holder farmers in Zimbabwe.

[19] Hellin, J. (2016). Better land husbandry: from soil conservation to holistic land management. CRC Press.

[20] Manjur, B., Abebe, T., \& Abdulkadir, A. (2014). Effects of scattered F. albida (Del) and C. macrostachyus (Lam) tree species on key soil physicochemical properties and grain yield of Maize (Zea Mays): a case study at umbulo Wacho watershed, southern Ethiopia. Southern Ethiop. J. Agric. Res, 3(3), pp.063-073.

[21] Abebe, G. (2018). Household Food Insecurity in the Sidama Zone of Southern Ethiopia. Factors, coping and Adaptation Strategies.

[22] Kidane, L., Gebremedhin, G.. \& Beyene, T. (2018). Ethnobotanical study of medicinal plants in Ganta Afeshum District, Eastern Zone of Tigray, Northern Ethiopia. Journal of ethnobiology and ethnomedicine, 14(1), p. 64.

[23] Agarwal, B. (2014). Food sovereignty, food security and democratic choice: Critical contradictions, difficult conciliations. Journal of Peasant Studies, 41(6), pp. 1247-1268.

[24] Geertsema, et al. (2016). Actionable knowledge for ecological intensification of agriculture. Frontiers in Ecology and the Environment, 14(4), pp. 209-216.

[25] Weiwei, et al. (2014). Traditional agroforestry systems: one type of globally important agricultural heritage systems. Journal of Resources and Ecology, 5(4), pp. 306-313.

[26] Abebe, T., Wiersum, K. F., \& Bongers, F. (2010). Spatial and temporal variation in crop diversity in agroforestry homegardens of southern Ethiopia. Agroforestry systems, 78(3), pp. 309-322.

[27] Guiang, E. S., Borlagdan, S. B., \& Pulhin, J. M. (2001). Community-based forest management in the Philippines: a preliminary assessment. Institute of Philippine Culture, Ateneo de Manila University.

[28] Leakey, R. R. (2010). Agroforestry: a delivery mechanism for multi-functional agriculture. Handbook on agroforestry: man- 
agement practices and environmental impact, pp. 461-471.

[29] Sinclair, F. L., ed. (2013). Agroforestry: Science, Policy and Practice: Selected papers from the agroforestry sessions of the IUFRO 20th World Congress, Tampere, Finland, 6-12 August 1995 (Vol. 47). Springer Science \& Business Media.

[30] Zwane, E. M. (2012). Does extension have a role to play in rural development? South African Journal of Agricultural Extension, 40(1), pp.16-24.

[31] Rogers, E. M. (2010). Diffusion of innovations. Simon and Schuster.

[32] Jama, et al. (2008). Comparing the "Big Five": A framework for the sustainable management of indigenous fruit trees in the drylands of East and Central Africa. Ecological indicators, 8(2), pp. 170-179.

[33] Kassie, et al. (2009). August. Adoption of sustainable agriculture practices: Evidence from a semarid region of Ethiopia. In Natural Resources Forum (Vol. 33, No. 3, pp. 189-198). Oxford, UK: Blackwell Publishing Ltd.

[34] Akinnifesi, et al. (2008). Contributions of agroforestry research to livelihood of smallholder farmers in Southern Africa: 1. Taking stock of the adaptation, adoption and impact of fertiliser tree options. Agricultural Journal, 3(1), pp.58-75.

[35] Atnafe, A. D., Ahmed, H. M., \& Adane, D. M. (2015). Determinants of adopting techniques of soil and water conservation in Goromti Watershed, Western Ethiopia. Journal of Soil Science and Environmental Management, 6(6), pp. 168-177.

[36] Glover, E. K., Ahmed, H. B., \& Glover, M. K. (2013). Analysis of socio-economic conditions influencing adoption of agroforestry practices. International Journal of Agriculture and Forestry, 3(4), pp. 178-184.

[37] Wafuke, S. (2012). Adoption of agroforestry technologies among small scale Farmers in Nzoia location, Lugari district, Kenya (Doctoral dissertation, Egerton University). 